scale. The follow up (FUP) was 5 years. Individual patients' files described 90 parameters. Instrumental diagnostic methods included plain radiography of knee joints, dual energy X-ray absorptiometry (DEXA) of lumbar spine L1-4, femoral neck and subchondral tibia, ultrasound (US) and MRI examination of knee joints. $\mathrm{OA}$ progression was verified based on evolution of radiological stage. At baseline 24 pts (7\%) had stage I OA, 227 (66\%) - stage II, and 93 (27\%) - stage III. Discriminant analysis was applied to verify most reliable RF predicting radiological progression.

Results: Radiological progression was documented in $45 \%$ participants during 5 year FUP. The groups with and without progression were comparable in terms of age and disease duration ( $»<0,05)$. Pts who progressed suffered more intensive knee pain $-68(52-72)$ vs $41(30-63) \mathrm{mm}$, » $<0,01$, had higher body weight $82(77-93)$ vs $72(65-81) \mathrm{kg}$, » <0,01, had higher rates of knee synovitis (US) $44 \%$ vs $26 \%, "=0,03,(\mathrm{RR}=1,67,95 \% \mathrm{Cl} 1,07-2,59)$ and mid-tibia bone marrow oedema $-60 \%$ vs $28 \%$, » $<0,01$ ( $R R=2,12,95 \% \mathrm{Cl} 1,34-3,35)$. The discriminant analysis showed that knee pain, excessive body weight, synovitis and mid-tibia bone marrow oedema (MRI) can be considered as predictors of OA radiological progression. A model capable of predicting OA course in an individual patient with high $88 \%$ accuracy, $87.7 \%$ sensitivity and $70 \%$ specificity has been developed based on identified RF and their coefficients. Area under the ROC-curve 0, 921 (95\% Cl 0,875-0,966).

\begin{tabular}{|l|c|}
\hline \multicolumn{1}{|c|}{$\mathrm{RF}$} & $\begin{array}{c}\text { Discriminant } \\
\text { function } \\
\text { coefficients }\end{array}$ \\
\hline $\begin{array}{l}\text { Knee pain } \\
\text { Body } \\
\text { weight }\end{array}$ & 0,03 \\
\hline $\begin{array}{l}\text { US: } \\
\text { synovitis }\end{array}$ & 0,03 \\
\hline $\begin{array}{l}\text { MRI: bone } \\
\text { marrow } \\
\text { edema }\end{array}$ & 0,34 \\
\hline \begin{tabular}{l} 
Constant \\
\hline
\end{tabular} & 6,22 \\
\hline
\end{tabular}

Conclusions: Knee pain, excessive body weight, synovitis and bone marrow oedema should be considered as key RF predicting knee OA radiological progression.

Disclosure of Interest: None declared

DOI: 10.1136/annrheumdis-2018-eular.2089

\section{FRI0546 RELATIVE EFFICACY OF DIFFERENT EXERCISES IN KNEE AND HIP OSTEOARTHRITIS}

S.L. Goh ${ }^{1,2}$, M.S.M. Persson ${ }^{2}$, J. Stocks ${ }^{2}$, Y.F. Hou ${ }^{3}$, J.H. Lin ${ }^{3}$, M. Hall ${ }^{2}$, M. Doherty ${ }^{2}$, W. Zhang ${ }^{2}$. 'University of Malaya, Kuala Lumpur, Malaysia; ${ }^{2}$ University of Nottingham, Nottingham, UK; ${ }^{3}$ Peking University, Peking, China

Background: All osteoarthritis (OA) guidelines recommend exercise as one of the core treatments for OA. ${ }^{1}$ However, it is unclear whether one exercise is better than another and for which outcome. Due to the limited evidence that compare different types of exercise, we undertook this network meta-analysis (NMA).

Objectives: To determine the relative efficacy of different exercises for pain and self-reported function at (or nearest to) eight weeks.

Methods: Nine electronic databases were searched for eligible randomised controlled trials (RCTs) that compared any types of exercise. The search was first performed in December 2015 and was updated in December 2017. Studies comparing exercise with usual care or with another exercise were included for this NMA. Common comparators such as usual care were used to network different types of exercise. Frequentist NMA was used to estimate the relative effect size (ES), i.e. standard mean difference and its $95 \%$ confidence interval $(\mathrm{Cl}){ }^{2}$

Results: 217 RCTs $(n=20419)$ met the inclusion criteria. Of these, 89 trials $(n=7070 ; 97$ comparisons) were analysed for pain outcome (figure 1), whilst 87 trials ( $n=7039 ; 97$ comparisons) were analysed for function. Mind-body exercise was the most effective for pain relief, closely followed by aerobic exercise (See the last column, table 1). While mind-body remained the best for improving function, strength and flexibility/skills exercise were better than aerobic exercise (See the last row, table 1). Single exercises were consistently better than mixed exercise.

Table 1 Effect size (95\% confidence interval) between different exercises
Pain outcomes:

\begin{tabular}{lccccc}
\hline Mind-body & 0.05 & 0.42 & 0.51 & 0.66 & 1.07 \\
& $(-0.49,0.60)$ & $(-0.04,0.87)$ & $(0.01,1.02)$ & $(0.23,1.09)$ & $(0.65,1.49)$ \\
\hline 0.23 & Aerobic & 0.36 & 0.46 & 0.61 & 1.02 \\
$(-0.37,0.84)$ & & $(-0.02,0.75)$ & $(0.0-0.91)$ & $(0.23-0.98)$ & $(0.65-1.39)$ \\
0.1 & -0.13 & Strength & 0.09 & 0.24 & 0.65 \\
$(-0.40,0.60)$ & $(-0.57,0.31)$ & & $(-0.22,0.4)$ & $(-0.02,0.50)$ & $(0.44-0.86)$ \\
0.16 & -0.07 & 0.06 & Flex/Skills & 0.15 & 0.56 \\
$(-0.40,0.72)$ & $(-0.58,0.43)$ & $(-0.28,0.40)$ & & $(-0.17,0.47)$ & $(0.25-0.87)$ \\
0.4 & 0.17 & 0.3 & 0.24 & Mixed exercise & 0.41 \\
$(-0.08,0.87)$ & $(-0.25,0.58)$ & $(0.01-0.59)$ & $(-0.10,0.58)$ & & $(0.23-0.59)$ \\
0.78 & 0.55 & 0.68 & 0.62 & 0.38 & Usual Care \\
$(0.32-1.25)$ & $(0.14-0.96)$ & $(0.45-0.92)$ & $(0.28-0.96)$ & $(0.17-0.60)$ & \\
\hline \multicolumn{5}{r}{}
\end{tabular}

\section{Functional outcomes:}

Note: Exercises are in order from the top left to the bottom right. Pain outcomes are at the top and functional outcomes are at the bottom. Numbers in each cell represent effect size (95\% confidence interval) between higher comparator versus lower comparator.

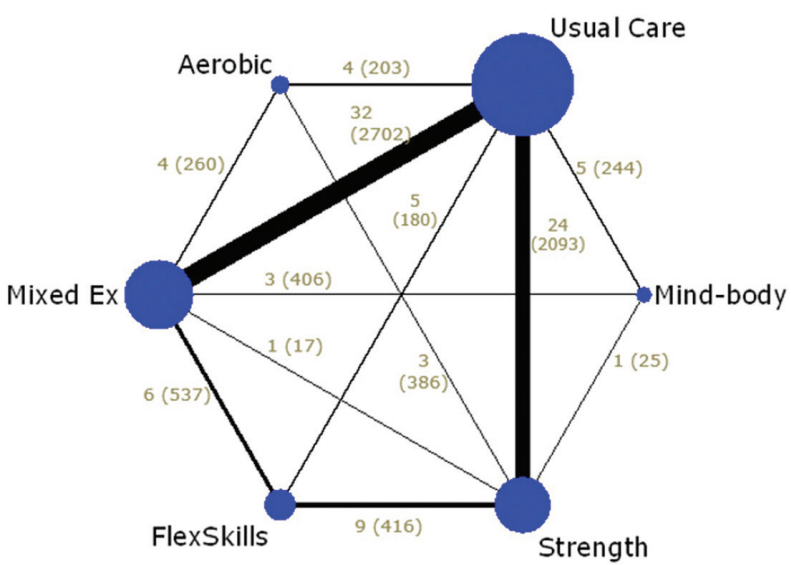

Abstract FRI0546 - Figure 1. Network diagram for pain

Aerobic: walking, cycling; FlexSkills: flexibility exercise, neuromotor training, proprioceptive training; Strength: resistance training; Mind-body: Tai-chi, Yoga; Mixed Ex: multi-component exercises

Conclusions: This exercise hierarchy and their relative efficacy provide a useful basis for patients and clinicians to select the most appropriate exercise whilst taking treatment goals (pain relief or functional improvement) and patient preference into consideration. The reason for the relative poor efficacy of mixed exercise war rants investigation as it contradicts current guidelines.

\section{REFERENCES :}

[1] Fernandes L, et al. EULAR recommendations for the non-pharmacological core management of hip and knee osteoarthritis. Annals of the Rheumatic Diseases 2013;72(7):1125-1135.

[2] Caldwell DM. An overview of conducting systematic reviews with network meta-analysis. Systematic Reviews 2014;3(109):1-4.

Disclosure of Interest: None declared

DOI: 10.1136/annrheumdis-2018-eular.3370

\section{FRI0547 IN HAND OSTEOARTHRITIS, DECREASE IN SYNOVITIS RESULTS IN LESS JOINT PAIN; A LONGITUDINAL MAGNETIC RESONANCEIMAGING STUDY}

S. Van Beest ${ }^{1}$, W. Damman ${ }^{1}$, R. Liu ${ }^{1}$, M. Reijnierse ${ }^{2}$, F.R. Rosendaal ${ }^{3}$, J. L. Bloem ${ }^{2}$, M. Kloppenburg ${ }^{1,3} .{ }^{1}$ Rheumatology; ${ }^{2}$ Radiology; ${ }^{3}$ Clinical Epidemiology, Leiden University Medical Center, Leiden, Netherlands

Background: Current treatment options to alleviate pain in hand osteoarthritis $(\mathrm{OA})$ are limited in number, efficacy, and safety. Local inflammation and subchondral bone activity are interesting as potential treatment targets, since synovitis and bone marrow lesions (BMLs) have the ability to change over time and were shown to have positive cross-sectional associations with joint tenderness. 